\title{
Pregnancy and kidney disease: from medicine based on exceptions to exceptional medicine
}

\author{
Giorgina Barbara Piccoli ${ }^{1,2} \cdot$ Gianfranca Cabiddu $^{3}$
}

Received: 30 March 2017 / Accepted: 3 April 2017 / Published online: 22 April 2017

(C) Italian Society of Nephrology 2017

\begin{abstract}
The Webster dictionary defines exception as an anomaly, a person or thing that does not follow a rule, while the adjective exceptional has a different nuance, and means "above average". These two words may describe how obstetric nephrology has shifted from the description of very rare cases, to the development of a complex new and fascinating branch of medicine, that counterbalances obstetricians' usually optimistic outlook by focusing on subtle challenges posed by chronic diseases, and mitigate the frequently grim approach of nephrologists, with a message of hope: women with kidney disease can have the same basic life goals as healthy women their age. Although studies relating to kidney disease in pregnancy are being published more frequently, not all questions have been considered or answered, and clinicians are often challenged by a lack of detailed information and practical guidelines. Thus in this complex, difficult, but also fascinating and evolving panorama, the Journal of Nephrology is publishing a issue dedicated to obstetric nephrology, in an attempt to contribute to the development of this field, with the specific aim of offering practical insights and critical contributions capable of helping clinicians in the management of these "exceptional exceptions".
\end{abstract}

This article is part of the topical collection on Obstetric Nephrology.

Giorgina Barbara Piccoli

gbpiccoli@yahoo.it

1 Department of Clinical and Biological Sciences, University of Torino, Turin, Italy

2 Nephrologie, Centre Hospitalier Le Mans, Avenue Roubillard, 72000 Le Mans, France

3 Nephrology, Azienda Ospedaliera Brotzu, Cagliari, Italy “...ninna nanna, ninna oh,

questo bimbo a chi lo do?

...

Lo darò al lupo nero,

Che lo tiene un anno intero

Lo darò al cavallo bianco,

Che lo culla finch'è stanco

Lo darò alla sua mamma,

Che gli canta la ninna nanna".

Ninna nanna popolare italiana

“... Lullaby, oh lullaby,

Who should I give this child to?

...

I'll give him to the black wolf,

Who will keep him for a year.

I'll give him to the white horse,

Who will rock him till he's tired.

I'll give him to his mammy,

Who will sing him this lullaby."

\section{Traditional Italian lullaby}

The Webster dictionary defines exception as an anomaly, a person or thing that does not follow a rule, while the adjective exceptional has a different nuance, and means "above average". These two words may describe how obstetric nephrology has shifted from the description of very rare cases, to the development of a complex new and fascinating branch of medicine, that counterbalances obstetricians' usually optimistic outlook by focusing on subtle challenges posed by chronic diseases, and mitigate the frequently grim approach of nephrologists, with a message of hope: women with kidney disease can have the same basic life goals as healthy women their age [1, 2] (Fig. 1).

Additionally, acute kidney diseases in pregnancy, from preeclampsia and HELLP syndrome, to acute 


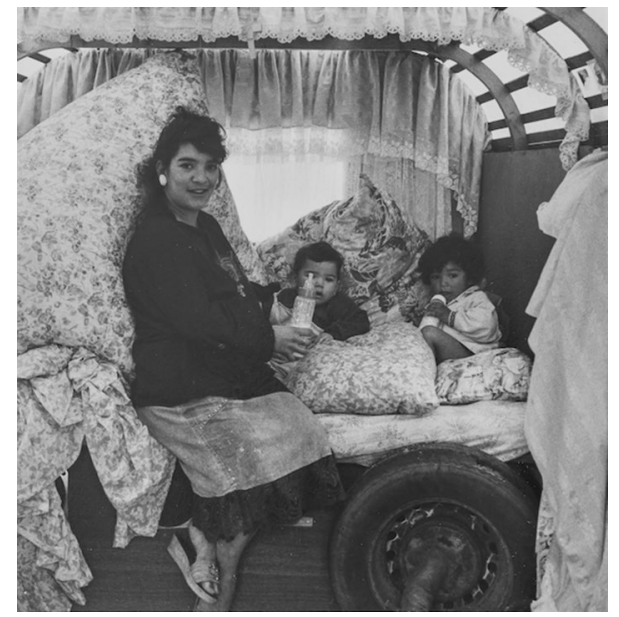

Fig. 1 Jean Yves Blais: Gipsy mother. 2000 about, Sarthe, France. Jean Yves Blais is a French voyager and photographer. I asked him how he choses the subjects he photographs, and he answered: "I take pictures of people I admire". "I admire gipsies for their pride and courage of remaining themselves in a changing world". Thus we chose this image in honour of the courage and pride of the many women who chose to have a child in spite of their chronic diseases. Courtesy of the Author

pyelonephritis and haemolytic uremic syndrome, have not disappeared in developed countries and are a great challenge, and a major cause of death during pregnancy, in the emerging world [3-6]. The growing awareness of the importance of kidney diseases, beginning in their earliest, non-symptomatic phases, often associated with older age of women giving birth for the first time, and the increased use of assisted fertilisation techniques (often in older women) are factors that have increased the reported incidence and improved the diagnosis of chronic kidney diseases in pregnancy, especially in in the more developed nations [7, 8].

In this context, complex ethical problems may arise from how we define the "maximum" risk at which a patient should be attempt pregnancy, the risk of short- and longterm problems for the infant, given the potentially severe problems linked to prematurity and the higher incidence of metabolic diseases, hypertension, and the possibility of kidney diseases in premature or small for gestational age children $[9,10]$. Conversely, the diffusion of nephrology in settings with limited resources, where pregnancy is often the first and only occasion for a timely diagnosis of chronic kidney disease, but where the prevalence of kidney diseases is significantly higher, in particular in the lowest socio-economic strata, highlights need for planning future management, which once more gives rise to controversial practical and ethical issues [3, 11].

Although studies relating to kidney disease in pregnancy are being published more frequently, not all questions have been considered or answered, and clinicians are often challenged by a lack of detailed information and practical guidelines [12].

Thus in this complex, difficult, but also fascinating and evolving panorama, the Journal of Nephrology sought and is publishing this issue dedicated to obstetric nephrology, in an attempt to contribute to the development of this field, with the specific aim of offering practical insights and critical contributions capable of helping clinicians in the management of these "exceptional exceptions".

The thematic issue will be divided into three main streams:

- acute kidney diseases in pregnancy, including preeclampsia and its short- and long_term effects on kidney function;

- chronic kidney diseases in pregnancy, optimally including both their diagnosis and clinical management;

- ethical issues in obstetric nephrology.

We have invited experts in the field to contribute and also to comment on selected innovative contributions by others and are pleased to inform our readers that the opening paper in the chronic kidney disease stream, on historic moments in the development of obstetric nephrology, will be a contribution by two giants and pioneers in obstetric nephrology, Professors Marshall Lindheimer and John Davison, whose long friendship (over 40 years) also demonstrates the importance of cooperation in new developments in medicine [13-15].

The acute kidney disease series will start with three contributions from experts working in developed and developing countries, to remind us of the importance of social context in the management and development of these diseases, with one paper on the Italian "best practices" for the management of preeclampsia by the nephrologist, and a physiopathologic reflection on why kidneys may fail post partum.

This issue will contain a variety of articles ranging from treatises on specific topics to case reports that demonstrate a principle or stimulate discussions relevant to management of our patients.

In this same line, we have invited recognized authorities to comment on particular cases, and to give practical examples of the common lines and different approaches to crucial issues such as when to start dialysis in pregnancy, when to perform a kidney biopsy or when and which empiric treatment should be undertaken.

We are also eager to learn from your experience, and we hope that this initiative will also serve to enhance existing collaborations and give rise to new ones, since, especially in developing fields, as the English say, "two heads are better than one", while according to Spaniards and Italians, "four eyes see more than two"... (Fig. 2). 


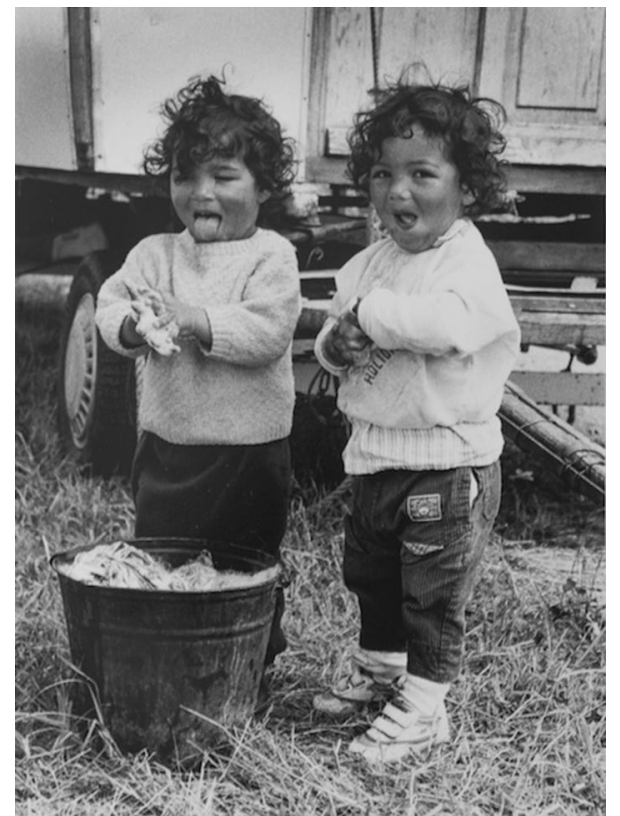

Fig. 2 Jean Yves Blais: Four eyes see more than two. 2000 about, Sarthe, France. The young playful gipsies are cousins, and were photographed in the same period as the young mother depicted above; one of them recently asked Mr. Blais to make some pictures of his own new-born child. This image, chosen to end our editorial with a smile, is dedicated to the two life-long friends Marshall Lindheimer and John Davison

Acknowledgements We are deeply thankful to Jean-Yves Blais, for the permission to reproduce his photographs.

\section{Compliance with ethical standards}

Conflict of interest The authors declare that they have no conflict of interest.

Funding No funding was obtained for this editoral paper.

Ethical approval This article does not contain any studies with human participants performed by any of the authors.

\section{References}

1. Jim B, Hou S (2013) Pregnancy and kidney disease-the miracle continues against all odds. Adv Chron Kidney Dis 20(3):206-208
2. Hall M (2016) Pregnancy in women with CKD: a success story. Am J Kidney Dis 68(4):633-639

3. Prakash J, Pant P, Prakash S, Sivasankar M, Vohra R, Doley PK, Pandey LK, Singh U (2016) Changing picture of acute kidney injury in pregnancy: study of 259 cases over a period of 33 years. Indian J Nephrol 26(4):262-267

4. Liu YM, Bao HD, Jiang ZZ, Huang YJ, Wang NS (2015) Pregnancy-related acute kidney injury and a review of the literature in China. Intern Med 54(14):1695-1703

5. Bentata Y, Housni B, Mimouni A, Azzouzi A, Abouqal R (2012) Acute kidney injury related to pregnancy in developing countries: etiology and risk factors in an intensive care unit. J Nephrol 25(5):764-75.

6. Hildebrand AM, Liu K, Shariff SZ, Ray JG, Sontrop JM, Clark WF, Hladunewich MA, Garg AX (2015) Characteristics and outcomes of AKI treated with dialysis during pregnancy and the postpartum period. J Am Soc Nephrol 26(12):3085-3091

7. Piccoli GB, Cabiddu G, Attini R, Vigotti FN, Maxia S, Lepori N et al (2015) Risk of adverse pregnancy outcomes in women with CKD. J Am Soc Nephrol 26(8):2011-2022

8. Zhang JJ, Ma XX, Hao L, Liu LJ, Lv JC, Zhang H (2015) A systematic review and meta-analysis of outcomes of pregnancy in CKD and CKD outcomes in pregnancy. Clin J Am Soc Nephrol 10(11):1964-1978

9. Piccoli GB, Postorino V, Cabiddu G, Ghiotto S, Guzzo G, Roggero S, 'Kidney and Pregnancy Study Group' of the 'Italian Society of Nephrology'; 'Kidney and Pregnancy Study Group' of the 'Italian Society of Nephrology' et al (2015) Children of a lesser god or miracles? An emotional and behavioural profile of children born to mothers on dialysis in Italy: a multicentre nationwide study 2000-12. Nephrol Dial Transpl 30(7):1193-1202

10. Bayman E, Drake AJ, Piyasena C (2014) Prematurity and programming of cardiovascular disease risk: a future challenge for public health? Arch Dis Child Fetal Neonatal Ed 99(6):F510-F514

11. Caplin B, Jakobsson K, Glaser J, Nitsch D, Jha V, Singh A, Correa-Rotter R, Pearce N (2017) International collaboration for the epidemiology of eGFR in low and middle income populationsrationale and core protocol for the disadvantaged populations eGFR epidemiology study (DEGREE). BMC Nephrol 18(1):1

12. Cabiddu G, Castellino S, Gernone G et al (2016) A best practice position statement on pregnancy in chronic kidney disease: the Italian Study Group on Kidney and Pregnancy. J Nephrol 29(3):277-303

13. Davison JM, Lindheimer MD (1978) Renal disease in pregnant women. Clin Obstet Gynecol 21(2):411-427

14. Lindheimer MD, Davison JM, Katz AI (2001) The kidney and hypertension in pregnancy: twenty exciting years. Semin Nephrol 21(2):173-189

15. Davison JM, Lindheimer MD (2011) Pregnancy and chronic kidney disease. Semin Nephrol 31(1):86-99 